Metals and Ceramics Division

CRADA Final Report

for

CRADA Number ORNL93-0242

The Mechanics of Creep

Deformation in Polymerderived Continuous Fiberreinforced Ceramic Matrix Composites

Edgar Lara-Curzio and K. L. More Oak Ridge National Laboratory

R. Boisvert and A. Szweda

Dow Corning Corporation

Date Published - October 2000

Prepared by the OAK RIDGE NATIONAL

LABORATORY

Oak Ridge, Tennessee 37831

Managed by

UT-BATTELLE

for the

U.S. DEPARTMENT OF ENERGY

under contract DE-AC05-00OR22725

APPROVED FOR PUBLIC RELEASE

UNLIMITED DISTRIBUTION 
C/ORNL93-0242

Metals and Ceramics Division

CRADA Final Report

for

CRADA Number ORNL93-0242

\title{
The Mechanics of Creep Deformation in Polymer-derived Continuous Fiber-reinforced Ceramic Matrix Composites ${ }^{1}$
}

\author{
Edgar Lara-Curzio and K. L. More
}

Oak Ridge National Laboratory

\author{
R. Boisvert and A. Szweda \\ Dow Corning Corporation
}

Date Published - January 2000

Prepared by the

OAK RIDGE NATIONAL LABORATORY

Oak Ridge, Tennessee 37831

Managed by

UT-BATTELLE

for the

U.S. DEPARTMENT OF ENERGY

under contract DE-AC05-00OR22725

\section{APPROVED FOR PUBLIC RELEASE \\ UNLIMITED DISTRIBUTION}

\footnotetext{
${ }^{1}$ This work was supported through a CRADA with Dow Corning Corporation, Midland Michigan, sponsored by the CFCC Program, Office of Industrial Technologies, U.S. Department of Energy, started under contract DE-AC05-96OR22464 with Oak Ridge National Laboratory, managed by Lockheed Martin Energy Research Corporation, and completed under contract DE-AC05-00OR22725, managed by UTBattelle, LLC.
} 


\section{Abstract}

The objective of this Cooperative Research and Development Agreement between Lockheed Martin Energy Research Corporation and Dow Corning Corporation was to study the effects of temperature, stress, fiber type and fiber architecture on the timedependent deformation and stress-rupture behavior of polymer-derived ceramic matrix composites developed by the Dow Corning Corporation.

Materials reinforced with CG-Nicalon ${ }^{\mathrm{TM}}$, Hi-Nicalon ${ }^{\mathrm{TM}}$ and Sylramic ${ }^{\circledR}$ fibers were evaluated under fast fracture, stress-relaxation, and stress-rupture conditions at temperatures between $700^{\circ} \mathrm{C}$ and $1400^{\circ} \mathrm{C}$ in ambient air and for stresses between 50 and $200 \mathrm{MPa}$. Some of the stress-rupture tests conducted as part of this program are among the longest-duration experiments ever conducted with these materials.

The possibility of using accelerated test techniques to evaluate the very-long term stress-rupture/creep behavior of these materials was investigated by means of stressrelaxation experiments. However it was found that because these materials exhibit nonlinear stress-strain behavior at stresses larger than the matrix cracking stress and because of environmentally-induced changes in the micro and mesostructure of the material, particularly at elevated temperatures, this approach is impractical. However, the results of stress-relaxation experiments will be useful to predict the behavior of these materials in applications where stresses are thermally-induced and therefore driven by strains (e.g., when components are subjected to thermal gradients).

The evolution of the microstructure of the fibers, matrix and fiber-matrix interface was studied as a function of stress and temperature, using analytical electron microscopy. The results from these analyses were essential to understand the relationships between environment, stress, temperature and processing on he microstructure and properties of these materials. 



\section{Objectives}

The original technical objectives of the CRADA were:

- to determine the effect of fiber type and fiber architecture on the time-dependent deformation of ceramic matrix composites densified by polymer-infiltration and pyrolysis by the Dow Corning Corporation.

- To study the evolution of the microstructure of the composite constituents when the composite is subjected to stress in air and simulated combustion environments at elevated temperatures.

On January 1997, an extension was requested and granted to redirect the focus of research in order to address two new objectives:

- The effect of exposure to air at intermediate temperatures on the thermal and mechanical stability of these composites.

- The effect of various compositions on the stability of polymer-derived SiC-based matrices.

\section{Meeting Objectives}

The original structure of the program had three phases, with each phase having a different number of tasks involving both ORNL and Dow Corning. Phases IV and V were added after the amendment to the scope of work on January 1997.

Phase I $\quad 3$ tasks

Phase II 6 tasks

Phase III 6 tasks

Phase IV 2 tasks

Phase V 2 tasks

All tasks were completed except task 3 of Phase I due to technical difficulties. 


\section{CRADA Benefit to DOE}

The results from this study have helped develop an understanding of the mechanisms responsible for the mode of deformation of continuous fiber-reinforced ceramic matrix composites. This understanding will facilitate the selection of materials, the design of components using these materials, and the development of a new generation of these materials, to address the demanding needs of the energy industries in the U.S. particularly in applications at elevated temperatures.

\section{Technical Discussion}

$\underline{\text { Introduction }}$

Continuous fiber-reinforced ceramic matrix composites (CFCCs) constitute a relatively new class of materials with the potential for retaining strength and exhibit tough behavior at elevated temperatures. The development of CFCCs has been driven to a great extent by the promise of substantial environmental and economic benefits if these materials are used in high-temperature industrial applications, particularly in the energy-related industries. The main attributes that make these materials attractive for these applications are their low density, their corrosion and wear resistance, and the potential for exhibiting dimensional stability and retention of strength at elevated temperatures. Most of the potential applications for these materials involve aggressive environments. For example, these materials are being considered for the fabrication of filters in coal-fired power plants that would be subjected to both oxidizing and reducing environments at elevated temperatures. These materials are also being considered for the manufacture of combustor liners for gas turbine engines. In this application stresses arise from thermal gradients through the wall of the component but the most severe conditions arise from being subjected to large heat fluxes, elevated temperature, and high pressure combustion environments. In most of these applications, these components are expected to last for tens of thousands of hours. 
In general, the strength and toughness of CFCCs are controlled by the reinforcing fibers and by fiber coatings. Therefore, an important part of this study was the investigation of the effects of the fiber type and fiber architecture on the time-dependent deformation of these materials and their retention of strength at elevated temperatures under stress. Another important element of this investigation was the determination of the thermal stability of the fibers and fiber coatings in these materials at temperatures and periods of time comparable to those of the potential applications, and the effect of various chemistry compositions on the thermal and structural stability of the matrix and composite.

\section{Experimental}

The effect of fiber and fiber architecture on the time-dependent deformation and stress-rupture behavior of polymer-derived CFCCs developed by the Dow Corning Corporation were investigated. Specimens with unidirectional, woven (0/90 fabric), and stacked lay-ups $( \pm 45)$ were evaluated to assess the contribution of the fibers and the matrix to the composite deformation. Evaluation of unidirectional $\left(0^{\circ}\right)$ specimens in tension allowed for the determination of the fiber contribution to the composite deformation whereas the evaluation of specimens with a $\pm 45^{\circ}$ lay-up were used to determine the contribution of the matrix to the deformation of the composite.

Tests were conducted with materials reinforced with various fibers such as ceramicgrade (CG) Nicalon ${ }^{\mathrm{TM}}$, Hi-Nicalon ${ }^{\mathrm{TM}}$ and Sylramic ${ }^{\mathrm{TM}}$. It was found that Hi-Nicalon ${ }^{\mathrm{TM}}$ and Sylramic $^{\mathrm{TM}}$ fibers exhibit both substantially higher creep-resistance and stiffness than CGNicalon $^{\mathrm{TM}}$ fibers. In addition, Hi-Nicalon ${ }^{\mathrm{TM}}$ and Sylramic ${ }^{\mathrm{TM}}$ fibers have the ability to better sustain the thermal excursions associated with the multiple infiltration and pyrolysis cycles required for the synthesis of the matrix. Therefore composites reinforced with these fibers tend to be, on average, stronger than composites reinforced with CG-Nicalon ${ }^{\mathrm{TM}}$ fibers. A benefit of reinforcing composites with stiffer fibers is that these composites exhibit an increase of the magnitude of the matrix cracking stress. F1 shows the stress- 
strain curves obtained from the monotonic tensile evaluation of composites with CGNicalon $^{\mathrm{TM}}$ and Hi-Nicalon ${ }^{\mathrm{TM}}$ fibers. Note that the latter are stiffer, stronger and have a higher proportional limit stress. F2 shows strain histories of tests conducted in air at $1200^{\circ} \mathrm{C}$ under a constant stress of $120 \mathrm{MPa}$ and clearly demonstrate the better dimensional stability of the composite reinforced with Hi-Nicalon ${ }^{\mathrm{TM}}$ fibers. F3 is a plot of the rate of deformation as a function of time and demonstrates an order of magnitude improvement in creep resistance of composites reinforced with Hi-Nicalon ${ }^{\mathrm{TM}}$ fibers when compared with composites reinforced with CG-Nicalon ${ }^{\mathrm{TM}}$ fibers.

The possibility of evaluating the long-term behavior of these composites from accelerated tests, (e.g.- stress-relaxation) was investigated. Stress-rupture tests were conducted at various temperatures and various initial stresses both larger and smaller than the matrix cracking stress. It was determined that this approach was not practical because these materials exhibit non-linear stress-strain behavior at stresses larger than the proportional limit stress and because these materials experience substantial microstructural changes induced by reactions with the environment.

The evolution of the microstructure of the fibers, matrix and interfaces was studied by means of analytical electron microscopy for specimens that had been mechanicallyevaluated at various stresses, temperatures and for various periods of time. Special emphasis was given to environmentally-induced microstructural changes in the composite constituents and how these impact the mechanical properties and performance of these materials.

\section{Conclusions}

The effect of fiber type and fiber architecture on the strength and time-dependent deformation of continuous fiber-reinforced ceramic matrix composites densified by the polymer infiltration and pyrolysis process were determined. 
The thermal and environmental stability of composite constituents was assessed through mechanical testing and microstructural characterization as a function of processing history and exposure in various environments at elevated temperatures.

\section{Report of Inventions}

There were no inventions developed under this agreement.

\section{Commercialization Possibilities}

The Dow Corning Corporation is currently offering some of the materials evaluated in this study on a commercial basis.

\section{Plans for Future Collaborations}

Informal collaborations are maintained between the parties, but no plans have been made for future formal collaborations. 


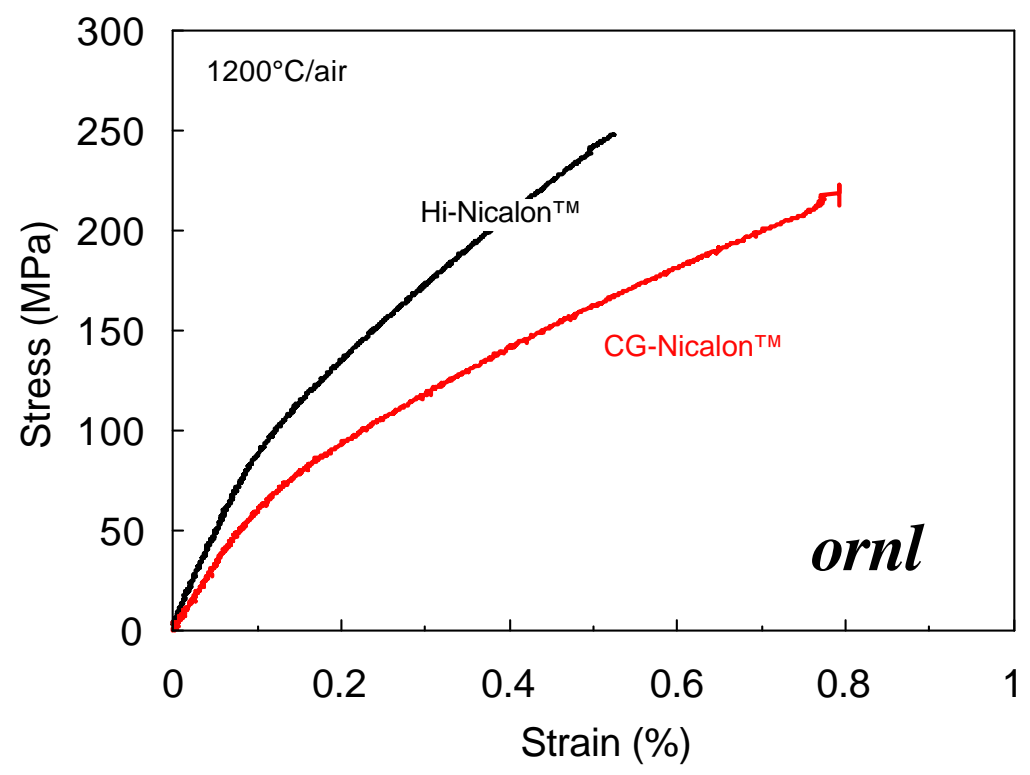

Figure 1. Monotonic tensile stress-strain curves for CG-Nicalon ${ }^{\mathrm{TM}}$ and Hi-Nicalon ${ }^{\mathrm{TM}}$ fiber-reinforced SiNCO matrix composites. Note the effect of higher stiffness of HiNicalon ${ }^{\mathrm{TM}}$ fibers.

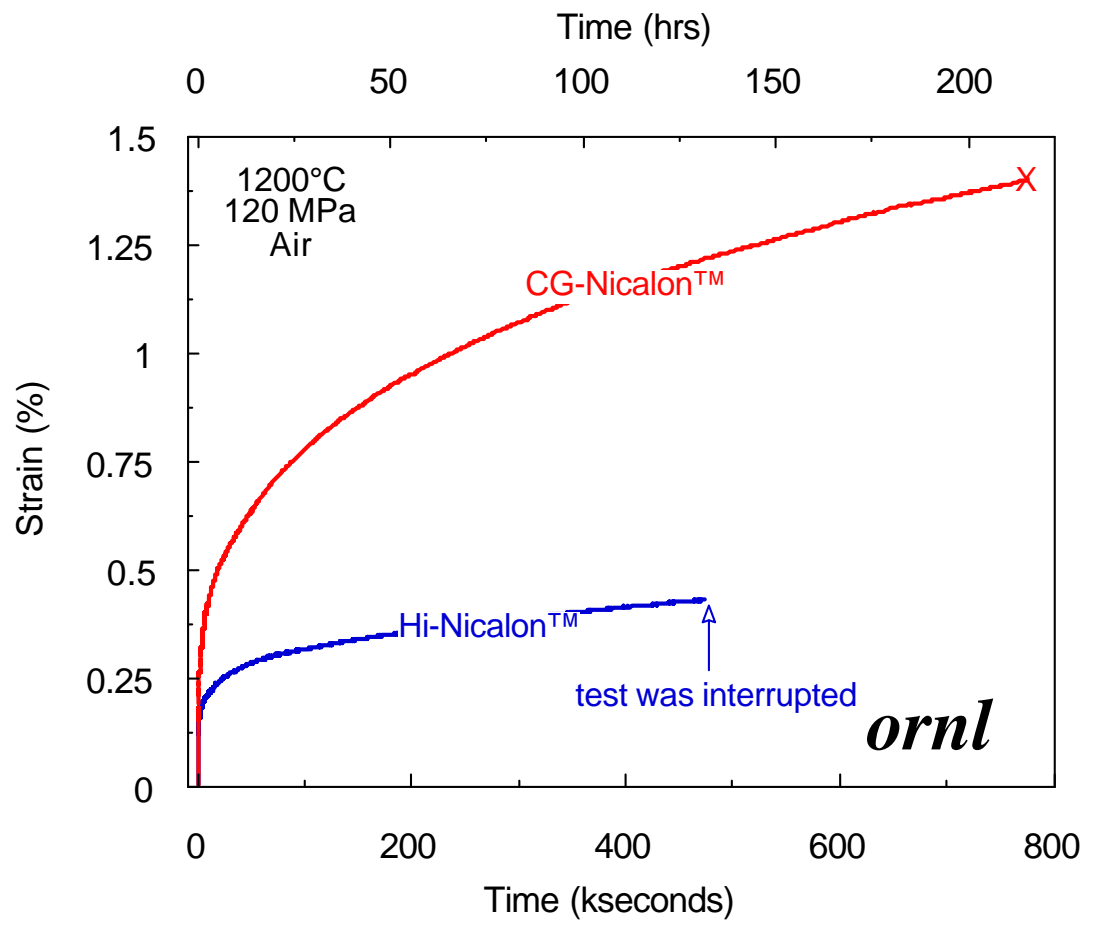

Figure 2. Strain histories recorded during creep testing of CG-Nicalon ${ }^{\mathrm{TM}}$ and $\mathrm{Hi}$ Nicalon ${ }^{\mathrm{TM}}$ fiber-reinforced SiNCO PIP matrix composites at $1200^{\circ} \mathrm{C}$ in air. Note that 
composites reinforced with Hi-Nicalon ${ }^{\mathrm{TM}}$ fibers exhibit significantly better dimensional stability.

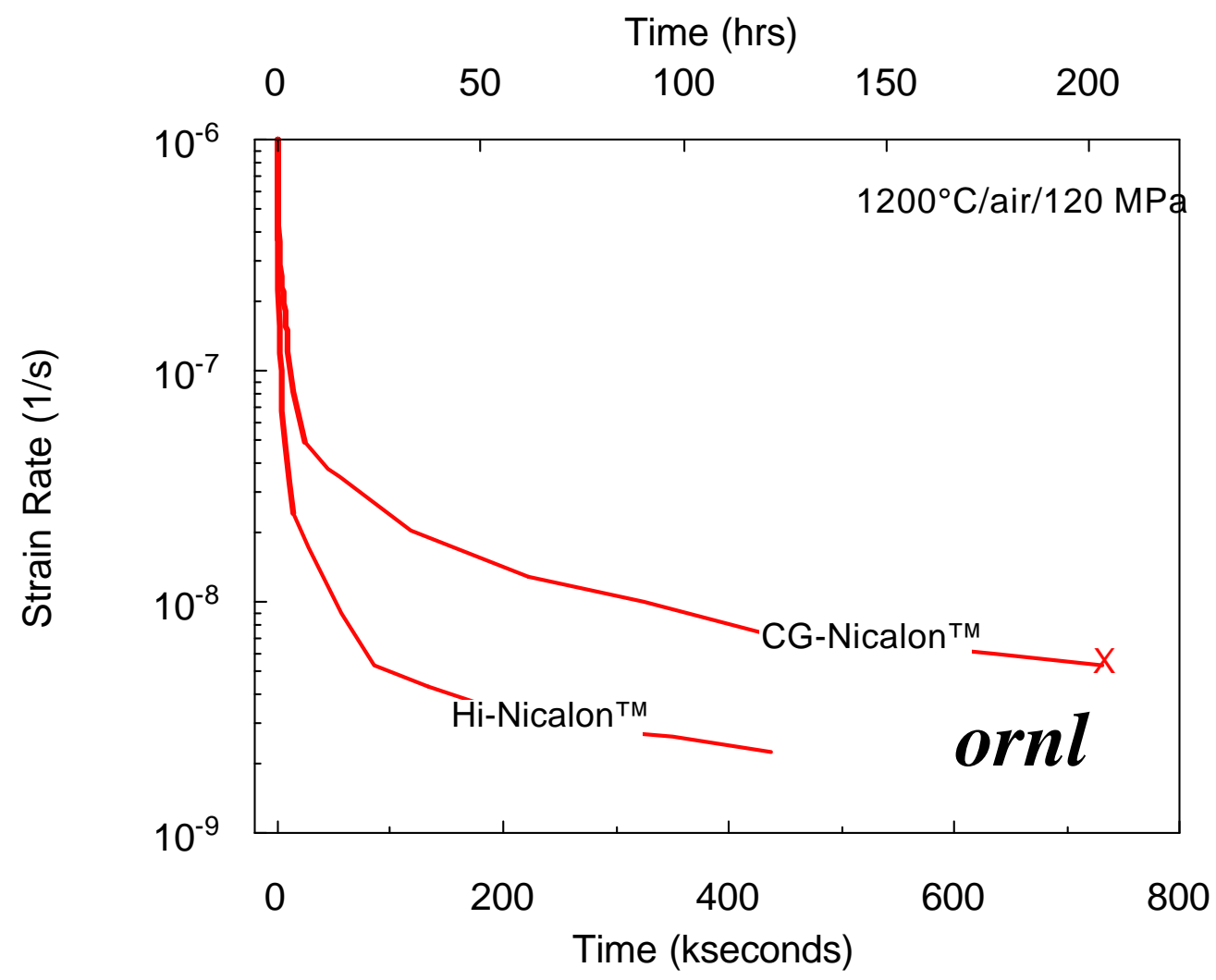

Figure 3. Plot of rate of deformation as a function of time for CG-Nicalon ${ }^{\mathrm{TM}}$ and $\mathrm{Hi}$ Nicalon ${ }^{\mathrm{TM}}$ fiber-reinforced SiNCO PIP matrix composites at $1200^{\circ} \mathrm{C}$ in air. Note the HiNicalon $^{\mathrm{TM}}$ fiber-reinforced composites are about one order of magnitude more resistant to deformation than composites reinforced with CG-Nicalon ${ }^{\mathrm{TM}}$ fibers. 


\section{INTERNAL DISTRIBUTION}

1. R. A. Bradley, 4500S, 6061

2. M. A. Karnitz, 4515,

3. E. Lara-Curzio, 4515,6069

4. K. L. More, 4515,6064

5. C. A. Valentine, $111 \mathrm{UNV}, 6429$

6. Dave Hamrin, $4500 \mathrm{~N}, 6285$

7-8. Lab Records, $4500 \mathrm{~N}, 6285$

\section{EXTERNAL DISTRIBUTION}

1. R. Boisvert, Dow Corning Corporation,

2. Deborah Haught, Program Manager, Cross-Cut Technologies, Office of Industrial Technologies, DOE, Washington, DC 20585, DOE

3. P. A. Carpenter, DOE-ORO, ORNL Site Office, P. O. Box 2008, Oak Ridge, Tennessee 37831-6269

4. R. Jones, Dow Corning Corporation,

5. M. H. Rawlins, Program Manager, DOE-ORO, Oak Ridge, TN 37831-6269

6. Merrill Smith, Program Manager, Waste Materials Management Division, Office of Industrial Technologies, U. S. Department of Energy, Washington, DC 20585

7. Office of Scientific and Technical Information, P. O. Box 62, Oak Ridge, Tennessee 37831

8. Office of Scientific and Technical Information, P. O. Box 62, Oak Ridge, Tennessee 37831

9. Work for Others Office, DOE-ORO, MS G209 